\title{
Resonant scattering by excited ions as an indicator of the precipitation of charged particles into the atmosphere
}

\author{
Vasily Bychkov ${ }^{1, *}$, Andrey Perezhogin ${ }^{1}$, and Ilya Seredkin ${ }^{1}$ \\ ${ }^{1}$ Institute of Cosmophysical Research and Radio Wave Propagation of the Far Eastern Branch of Rus- \\ sian Academy of Sciences, Paratunka, Russia
}

\begin{abstract}
The results of two-frequency lidar sounding of the atmosphere from the altitudes of 100-500 km are presented. The data were obtained in 2017 at a lidar site located in Kamchatka. One lidar channel is applied to investigate the aerosol formations in the middle atmosphere and to issue the resonance scattering on excited ions of atomic nitrogen in the upper atmosphere. Nd:YAG laser operating on the wavelength of $532 \mathrm{~nm}$ is used in this channel. A dye laser with tunable frequency is applied in the second channel. The wavelength of $561.1 \mathrm{~nm}$ corresponds to the chosen dipole transition between the excited states of atomic oxygen. Defined light-scattering layers were discovered in the region of $200-400 \mathrm{~km}$. They are caused by presence of excited states of atomic oxygen and nitrogen ions.

The possibility of reconstruction of excited ions Nh-profile and determination of precipitated electron fluxes spectra by the lidar method is shown. The possibility of manifesting resonance scattering and formation of imaginary aerosol layers in the middle atmosphere is discussed.

Keywords: atmosphere, ionosphere, lidar, sounding, scattering.
\end{abstract}

\section{Introduction}

Application of resonance scattering effect during laser radiation propagation in the upper atmosphere was first suggested in 1964-1965. It was suggested to use the resonance scattering on molecular nitrogen lines and radiation on one of sodium lines [1]-[3]. First experiments on laser sounding of atmospheric sodium at the heights of 80-100 km were carried out in 1968 [4]. For the metal ions, resonance scattering cross section has the order of $10^{-13} \mathrm{~cm}^{2} \mathrm{sr}^{-1}$. For the gas components the resonance scattering cross section has the values from $10^{-12} \mathrm{~cm}^{2} \mathrm{sr}^{-1}$ for helium atom to $10^{-21} \mathrm{~cm}^{2} \mathrm{sr}^{-1}$ for some electron transitions for molecular nitrogen.

Most investigations are devoted to the data on the layers of sodium, iron and nickel at the heights from 80 to $140 \mathrm{~km}$. Modern methods of lidar sounding give opportunity to measure the ion content, temperature, wind speed and the dynamics of concentration of chemical elements in the changing geophysical conditions of the upper atmosphere [5]-[7]. In the lidar investigations of the main gas components of the thermosphere, we should mention the papers [8],[9]. The authors announce the lidar to investigate excited states of molecular nitrogen ion. Based on the investigation results of possible transmissions between the excited

\footnotetext{
*e-mail: vasily.v.bychkov@gmail.com
} 
Table 1. Equipment

\begin{tabular}{lll}
\hline Transmitter 1 & Transmitter 2 & Receiver \\
\hline Laser Nd:YAG Brilliant-B & Dye Laser TDL-90 & Telescope Diameter 60 cm \\
Pulse Energy 400 mJ & Pulse Energy 100 mJ & PMT Hamamatsu H8259-01 \\
Wavelength 532.08 nm & Wavelength 561.107 nm & Photon Counters M8784-01 \\
Linewidth 0.040 nm & Linewidth 0.025 nm & Spatial resolution 1.5 km \\
& Pump Laser YG-982E & Filters Bandwidth 1 nm \\
\hline
\end{tabular}

states of molecular nitrogen ion, the operation wave lengths of $390.303 \mathrm{~nm}$ for the transmitter and $391.537 \mathrm{~nm}$ for the receiver were proposed.

The lidar station in Kamchatka composed of a laser Brilliant-B and a Newton telescope with the mirror diameter of $60 \mathrm{~cm}$ was put into operation in autumn 2007. The resonance scattering on atomic nitrogen excited ions at the wavelength of $532 \mathrm{~nm}$ was discovered in March 2008. Backscattering signals at the wavelength of $532 \mathrm{~nm}$ in the region of 100-300 $\mathrm{km}$ are presented in the papers [10]-[12]. Based on ionospheric and lidar observations it was shown that during the super thermal $(0.1-10 \mathrm{keV})$ electron precipitation into the atmosphere, the total lidar signal from the height region of $200-300 \mathrm{~km}$ can correlate with plasma content in the ionospheric F2 layer nighttime maximum region.

Analysis of the geophysical state accompanying the phenomenon allowed us to conclude that a possible physical mechanism explaining these correlations is the resonance scattering on excited nitrogen ions. The phenomenon was observed both during magnetically calm conditions and during geomagnetic disturbances. The resonance scattering on excited ions of atomic oxygen at the wavelength of $561.1 \mathrm{~nm}$ was purposefully investigated after lidar station modernization in 2010. The paper presents the results of two-frequency lidar sounding at the wavelengths of these components in autumn 2017.

\section{Hardware complex}

In the observations of 2017 a two-frequency lidar with Nd:YAG laser was used to generate the radiation at the wavelength of $532 \mathrm{~nm}$ and a dye laser to generate the radiation at the wavelength of $561.1 \mathrm{~nm}$ at the frequency of $10 \mathrm{~Hz}$. The lidar main parameters, applied in the experiments, are shown in Table 1.

In the light guide of the receiver the signal is divided into fluxes with a radiation wavelength of more than $532 \mathrm{~nm}$ and a short-wavelength part. The separated fluxes are further directed to the photo-cathodes of two PMTs connected to photon counters. To calibrate the laser TDL-90 radiation we apply a mercury lamp and a spectrophotometer Sp-2500i with a camera PicoStar HR12. The ionosphere state is controlled by the results of ionosonde «Parus A» measurements.

\section{Measuring method and data processing}

To exclude illumination from near-field signals in both lidar receiving channels, an electronic blocking of the photomultiplier with a pulse length of $140 \mu$ s was used. That corresponds to the exception of the data on the first $21 \mathrm{~km}$. The obtained lidar data are stored in the form of binary files with 10-second accumulation and enable us to make further summation over any time intervals. It usually takes 15 minutes according to the ionosonde operation mode.

We should put a focus on the role of the background signal measurement technique. Analysis of the total signal overnight showed that after 100-150 km the signal often keeps the 
inclination to the axis of heights up to $500-600 \mathrm{~km}$. For this reason separate measurements of the background signal were implemented in software. Measurements are made between each two laser pulses in $10 \mu$ s steps in the interval of 20-24 ms. The background signal measured in such a way does not contain any aftereffect pulses and is provided by good data accumulation. In 2017 the lidar sounding was carried out at the wavelength of 532.08 and 561.107 $\mathrm{nm}$. We investigated the scattering on electron transitions illustrated in Table 2 [13].

Table 2. Dipole transitions of excited ions of oxygen and nitrogen atoms falling within the radiation bands of lasers

\begin{tabular}{|l|l|l|l|l|l|l|l|l|l|}
\hline & $\begin{array}{l}\text { Compo- } \\
\text { nent }\end{array}$ & $\begin{array}{l}\text { Wavelength } \\
\text { Air }(\mathrm{nm})\end{array}$ & $\mathrm{A}_{k i}\left(\mathrm{~s}^{-1}\right)$ & Lower Level & Term & J & Upper Level & Term & J \\
\hline 1 & OII & 561.1072 & $2.14 \mathrm{e}+06$ & $2 s^{2} 2 p^{2}\left({ }^{1} \mathrm{~S}\right) 3 s$ & ${ }^{2} \mathrm{~S}$ & $1 / 2$ & $2 s^{2} 2 p^{2}\left({ }^{3} \mathrm{P}\right) 4 p$ & ${ }^{2} \mathrm{P}^{\circ}$ & ${ }^{1} / 2$ \\
\hline 2 & NIII & 532.0870 & $5.68 \mathrm{e}+07$ & $2 \mathrm{~s} 2 \mathrm{p}\left({ }^{4} \mathrm{P}^{o}\right) 3 \mathrm{p}$ & ${ }^{2} \mathrm{D}$ & $5 / 2$ & $\left.2 \mathrm{~s} 2 \mathrm{p}^{3} \mathrm{P}^{o}\right) 3 \mathrm{~d}$ & ${ }^{2} \mathrm{~F}^{o}$ & $7 / 2$ \\
\hline 3 & NII & 532.0958 & $2.52 \mathrm{e}+07$ & $2 \mathrm{~s} 2 \mathrm{p}^{2}\left({ }^{4} \mathrm{P}\right) 3 \mathrm{p}$ & ${ }^{5} \mathrm{P}^{\circ}$ & 1 & $2 \mathrm{~s} 2 \mathrm{p}^{2}\left({ }^{4} \mathrm{P}\right) 3 \mathrm{~d}$ & ${ }^{5} \mathrm{P}$ & 2 \\
\hline
\end{tabular}

Here OII is an ion $\mathrm{O}^{+}, \mathrm{NII}-$ ion $\mathrm{N}^{+}, \mathrm{NIII}-$ ion $\mathrm{N}^{++}$. The lines represented in Table 2 were chosen on the basis of the laser radiation band widths and ion line Doppler broadening at the ionospheric heights of $0.004 \mathrm{~nm}$ for the temperature of $800^{\circ} \mathrm{K}$.

\section{Experimental data}

Seven cases of backscattering at the both lidar channels were recorded at the wavelengths of 532 and $561 \mathrm{~nm}$ over the period from August to November 2017. The characteristic feature of all the data obtained during this period is the backscattering from the region of 200-400 km and its absence from the region of 100-200 km. In all the cases, the geomagnetic state was calm during the observations. In the work we used the data for September 5 and 23, 2017. The spatial-temporal distribution of the return signal received on September 5, 2017 in Fig. 1 is presented. It uses lidar data with a 15-minute accumulation and a spatial resolution of 1.5 $\mathrm{km}$. The background signal was subtracted.

The profile is smoothed in height by the moving average method with the window of 4.5 $\mathrm{km}$. Signal values are normalized to the factor $\mathrm{k}^{*} \mathrm{H}^{2}$, where $\mathrm{H}$ is the height, $\mathrm{k}=10^{-4}$. The total lidar signal $\mathrm{S}$ accumulated over a night and the same signal Sn normalized to the factor $\mathrm{k} * \mathrm{H}^{2}$, presented in the bottom part of the figure. Normalization by the squared altitude corresponds to the actual decrease of the received signal with increasing altitude. It is assumed that aerosol and molecular scattering are absent at an altitude of $100 \mathrm{~km}$. For the chosen value of the coefficient $\mathrm{k}=10^{-4}$ at an altitude of $100 \mathrm{~km}$, the signal coincided with the actually registered signal thereby improving visual data perception.

Resonance scattering registered on September 23, 2017 differs from the results of sounding on September 5 in one respect. During the sounding of the atmosphere, the lightscattering layer was observed twice - from 11:30 to 13:00 UTC and from 14:00 to the end of observations at 14:45 (the figure is not shown). The absence of a layer from 14 to 13 UTC makes it possible to visualize the dynamics of the lidar signal and ionospheric parameters during the appearance of increased light scattering (see Fig. 2). Fig. 2 illustrates the results of lidar and ionospheric measurements carried out on September 23, 2017.

Figure 2a was compiled on the basis of 15-minute accumulation data. The background signal was subtracted. The total signals on the 200-400 km layer at 532 (1) and 561 (2) nm correlate well and are almost identical.

Figure $2 b$ shows the variations in the critical frequencies of the F2 (1) and E (2) layers during lidar observations. The time of appearance of increased backscattering from the iono- 

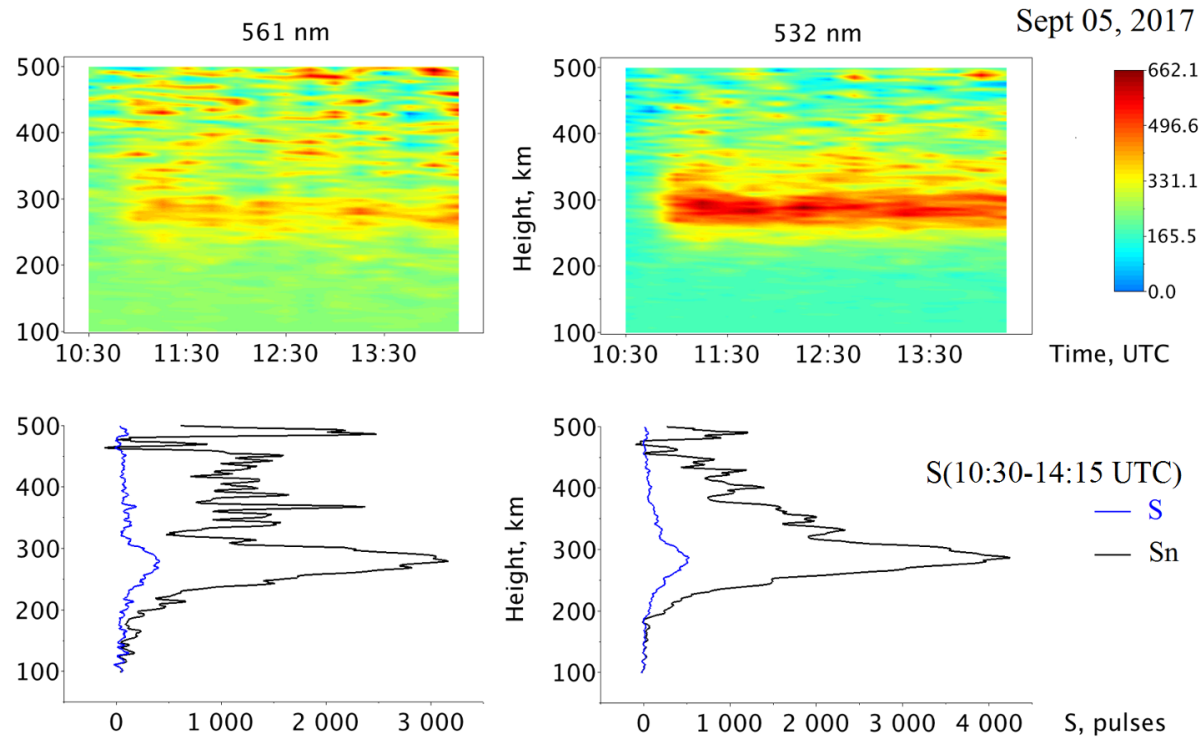

Figure 1. Lidar «signal-background» in the region of 100-500 km, total signal S and normalized signal Sn during the lidar observations on September 5, 2017
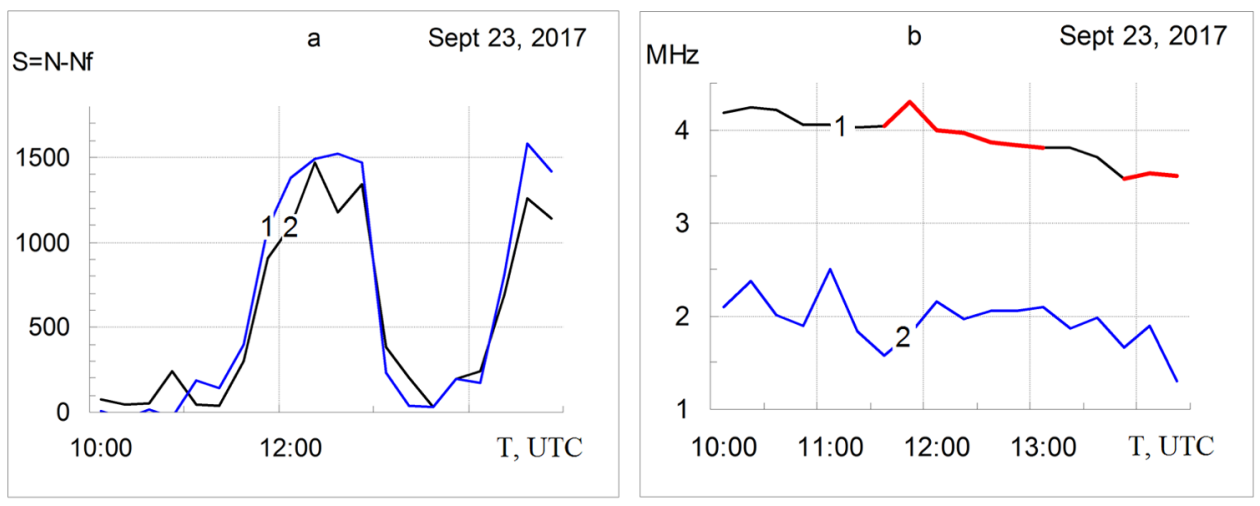

Figure 2. Lidar «signal-background» summed over the $200-400 \mathrm{~km}$ layer (a), and foF2 and foEs (b) during lidar observations on September 23, 2017

spheric layer F2 is marked in red. An increase in foF2 is observed with the appearance of resonant backscattering. The tracks of foF 2 were diffusive but defined quite well to determine foF2.

\section{Results and discussion}

\subsection{Lower thermosphere}

The following main features can be noted in the data of two-frequency lidar sensing obtained in August-November, 2017: 
- It was expected [14] that the lidar signal at a wavelength of $561 \mathrm{~nm}$ would be several times higher than the signal at a wavelength of $532 \mathrm{~nm}$ since the content of $\mathrm{O}^{+}$ions at altitudes $150-400 \mathrm{~km}$ is approximately two orders of magnitude higher than that of $\mathrm{N}^{+}$ions [15]. Lidar observations in autumn, 2017 demonstrated that the signal levels at two wavelengths were approximately identical. The values of the total signal at a wavelength of $532 \mathrm{~nm}$ were usually by $20-30$ percent higher.

- The altitude of the lidar return signal maximum did not correlate with the location of the F2 layer maximum. The lidar signal was maximal at altitudes $280-290 \mathrm{~km}$. This approximately corresponded to the altitude of the F2 layer maximum in the daytime and in the evening. At night, the maximum altitude increased, since the recombination rate in the lower layers is higher, whereas the ionization sources are absent. According to measurements with the ionosonde on September 5, 2017 the F2 layer maximum during recording of the light-scattering layer was located at altitudes $300-350 \mathrm{~km}$.

- Enhanced light scattering forming the second local maximum (Fig. 1) was observed for all total lidar signals at a wavelength of $561 \mathrm{~nm}$ at altitudes $300-400 \mathrm{~km}$. In all the cases, the signal at a wavelength of $532 \mathrm{~nm}$ decreased monotonically from its maximal value with increasing altitude.

Fig. 3 illustrates lidar signal profiles (a), and profiles of the ionization rate by precipitated electrons (b) were calculated based on the results of the papers [17],[18].

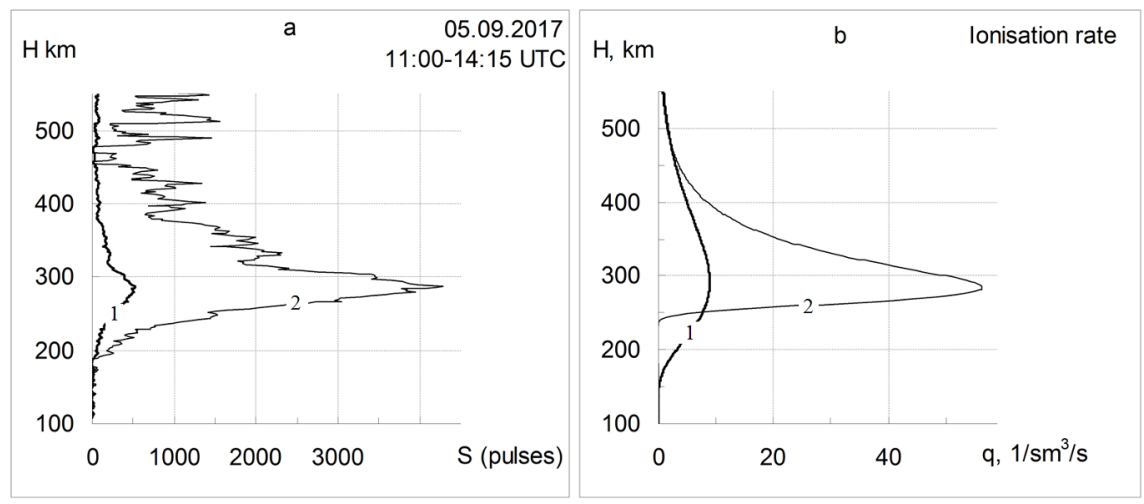

Figure 3. Lidar signal profiles observed on September 05, 2017 (a) and ionization rates for Maxwell and monoenergetic spectra of the precipitated electrons (b).

Fig. 3a shows total lidar signal S (1) obtained at the wavelength of $532 \mathrm{~nm}$ during the observation on September 5, 2017 and the same signal Sn (2) normalized to the geometric factor $\mathrm{k}^{*} \mathrm{H}^{2}$.

Fig. 3b illustrates the ionization rate calculated for the Maxwell spectra of electrons with the characteristic energy of $120 \mathrm{eV}(1)$ and for the monoenergetic beam of electrons with the energy of $330 \mathrm{eV}(2)$.

Electron energy was chosen so that the ionization rate maximum corresponded in height to the signal maximum $(280-290 \mathrm{~km})$. The concentrations of the neutral atmospheric $\mathrm{N}_{2}$, $\mathrm{O}$, and $\mathrm{O}_{2}$ components necessary for calculations were determined using the NRLMSISE00 model. The electron unknown flux was defined by the value $\mathrm{J}_{0}=10^{8} \mathrm{~cm}^{-2} \mathrm{~s}^{-1}$ which is characteristic for the auroral zone.

From the comparison of figures $3 \mathrm{a}, 3 \mathrm{~b}$, we can conclude that electron precipitations with the energies close to $330 \mathrm{eV}$ were observed. Figures 1, 3 explain the peculiarities of the 
obtained lidar signals. The altitude profile of the lidar signal correlates well with the altitude profile of the ionization rate. This means that the main signal maxima in both channels are mainly formed due to scattering on the excited ions formed as a result of photochemical reactions caused by the ionization process.

Scattering on $\mathrm{O}^{+}$ions of the $\mathrm{F} 2$ layer maximum excited by precipitated electrons starts to be manifested at altitudes $300-400 \mathrm{~km}$. There the second local maximum of scattering signal is formed (Fig.1). It is seen against the background of the decreasing signal from ions forming the main maximum and the increasing signal from excited ions of the F2 layer maximum. Above $350 \mathrm{~km}$, it is determined by scattering on ions $\mathrm{O}^{+}$, excited by precipitated electrons.

In [15] it was noted that about $60 \%$ of all $\mathrm{O}^{+}$ions are formed in the excited states. The data on the rate of forming some ions are also presented there. The rate of forming $\mathrm{O}^{+}$ions exceeds 3 folds the rate of forming $\mathrm{N}^{+}$ions. The $\mathrm{N}^{+}$ion fast annihilates in reactions with molecular oxygen; as a result, the concentration of these ions at altitudes $150-400 \mathrm{~km}$ is by 2 orders of magnitude less than that of the long-living $\mathrm{O}^{+}$ion. This explains the absence of the second maximum on the vertical profile of the signal from excited $\mathrm{N}^{+}$ions.

The fraction of laser pulse ions participating in resonant scattering can be estimated as a ratio of the half-linewidth of the excited component to the half-width of the laser spectrum. Taking into account the Doppler line broadening equal to $0.004 \mathrm{~nm}$ for both ions and the data of Table 1, it will be $10 \%$ for radiation at a wavelength of $532 \mathrm{~nm}$ and $15 \%$ for radiation at a wavelength of $561 \mathrm{~nm}$. The "useful" pulse energy will be 40 and $15 \mathrm{~mJ}$ for radiation at wavelengths of 532 and $561 \mathrm{~nm}$, respectively. The average content of excited ion "targets," proportional to the rates of forming of these ions, is three times higher for the oxygen ions. Therefore, nearly identical values of lidar signal maxima should be expected at two wavelengths.

The states of the "Lower level" in Table 2 are also excited. The radiation lifetime $\tau$ of each exited ion is determined as $\tau=1 / \Sigma \mathrm{A}_{k i}$ for all the states the transitions to which are possible. The search for all such states in the NIST Atomic Spectra Database yields values of $\tau$ equal to $1.06,1.42$, and $12.82 \mathrm{~ns}$ for $\mathrm{O}^{+}, \mathrm{N}^{++}$, and $\mathrm{N}^{+}$, respectively. The pulse durations $\mathrm{T}_{\text {pulse }}$ at wavelengths of 532 and $561 \mathrm{~nm}$ were 5 and $10 \mathrm{~ns}$, respectively. These values are of the same order of magnitude as the lifetimes of $\mathrm{O}^{+}$and $\mathrm{N}^{+}$excited states.

Laser radiation interaction with excited ions in a thin layer occurs during time $\mathrm{T}_{\text {pulse }}$. The excited ions, not only those that appeared in this volume during time $\mathrm{T}_{\text {pulse }}$, but also those appeared there during time $\tau$ immediately preceding the probe pulse arrival, are involved in the interaction. The interaction time should be estimated as the sum $\left(\mathrm{T}_{\text {pulse }}+\tau\right)$. For wavelengths of 532 and $561 \mathrm{~nm}$, these times will be 17.8 and $11 \mathrm{~ns}$, respectively. These values should be taken into account when interpreting the lidar signal level. The total signal should be proportional to the ion formation rate multiplied by $\left(\mathrm{T}_{\text {pulse }}+\tau\right)$. The results obtained are in agreement with these estimations.

\subsection{Middle atmosphere}

In the lidar studies of the middle atmosphere, the scattering ratio parameter $\mathrm{R}=(\beta \mathrm{a}+\beta \mathrm{m}) / \beta \mathrm{m}$ $=1+\beta \mathrm{a} / \beta \mathrm{m}$ was used, where $\beta \mathrm{a}, \beta \mathrm{m}$ are the aerosol and molecular scattering coefficients. The values of $\mathrm{R}$ above unity indicate the appearance of aerosol formations. In the ordinary state of the mesosphere there are no conditions for water condensation and aerosol formation.

In [16], the authors investigated strange correlations of the lidar signal $(532 \mathrm{~nm})$ resultant over the layers of $5 \mathrm{~km}$ in the mesosphere with the ionospheric parameter $\mathrm{f}_{\text {min }}$ observed in the winter season of 2008. According to the Demeter satellite data, flying near Kamchatka during the lidar observations, relativistic electron fluxes with the energy greater than $100 \mathrm{keV}$ 
were detected. Electron precipitations at latitude 53N are recorded at spans both east and west of Kamchatka. Calculation of the ionization rate from the spectrum obtained on the Demeter satellite showed that these fluxes could cause ionization with the maximum near 75 $\mathrm{km}$. The growth of $\mathrm{f}_{\min }$ could be caused by electron content increase in the mesosphere. The correlation of these values with the resultant lidar signal could be caused by the appearance of resonant scattering on atomic nitrogen excited ions.

When ionization sources appear, the conditions for the appearance of resonant scattering in the middle atmosphere are preserved. The Doppler broadening of the lines of nitrogen and oxygen ions determines the percentage of photons of the laser pulse capable of participating in resonant scattering. For a temperature of $800^{\circ} \mathrm{K}$ (F2 layer), it is $0.004 \mathrm{~nm}$. The Doppler broadening of the lines at the temperature of $200^{\circ} \mathrm{K}$ (mesopause) is $0.002 \mathrm{~nm}$ and is still quite sufficient for the formation of resonance scattering conditions. The electron-neutral collision frequency can be calculated from: $v[\mathrm{~N}]=0.81 * 10^{-10} *(\mathrm{~T} / \mathrm{M})^{1 / 2} * \mathrm{~N}\left(\mathrm{~s}^{-1}\right)$, where $\mathrm{T}$ is the temperature, $\mathrm{M}$ is the molecular weight, and $\mathrm{N}$ is the concentration of atmospheric particles [19]. Substituting the value of $\mathrm{N}$, for an altitude of $30 \mathrm{~km}$ equal $4 * 10^{17} \mathrm{~cm}^{-3}$, we get $v=2 * 10^{8} \mathrm{~s}^{-1}$, or $200 \mathrm{MHz}$. If we take into account that the frequency of ion-neutral collisions is at least two or three orders of magnitude lower than that of electrons, we can conclude that for excited ions with a radiation lifetime $10^{-8}-10^{-9} \mathrm{~s}$ the increase in the number of collisions at altitudes of $30 \mathrm{~km}$ and above does not play any noticeable role.

The obtained data illustrate this assumption. Figure 4 shows the scattering coefficient profiles plotted from data for September 5, 2017.

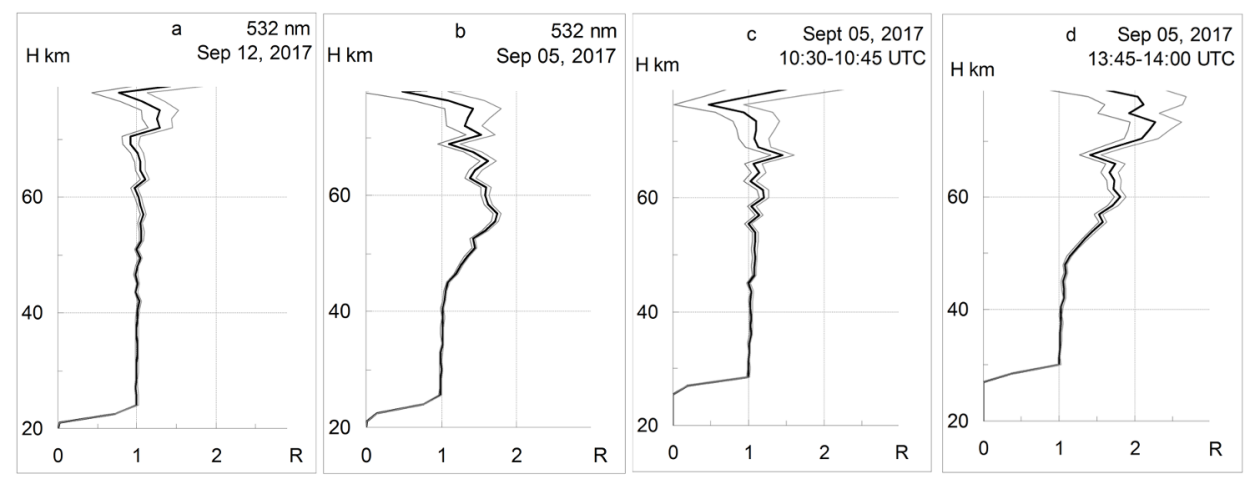

Figure 4. The scattering ratio profiles obtained on September 12 (a) and September 5 (b, c, d), 2017.

On the total profile for the night of September 12 the scattering ratio $\mathrm{R}$ is close to unity, aerosol formations in the mesosphere are absent. This is a typical profile for the autumn season. The scattering in the thermosphere is also not recorded. On the total profile for the night, received on September 5 (Fig. 4b), a scattering layer is observed in the region of 50-70 $\mathrm{km}$.

Profiles with accumulation of 15 minutes (Fig. 4c, 4d) were obtained:

- in Figure $4 \mathrm{c}$ before the appearance of a light-scattering layer in the thermosphere;

- in Figure 4d in his presence.

Scattering of aerosols at the altitudes of the mesosphere in August-September was observed rarely and only in the form of small increases in scattering in a narrow region of heights in the region of $60-80 \mathrm{~km}$. Layers in a wide range of heights with a maximum on the stratopause were not recorded once during the entire period of lidar observations from 2008 
to 2017. The appearance of aerosol scattering throughout the altitude region from 50 to 70 $\mathrm{km}$ requires an explanation.

Figure 5a shows the total lidar signal from which the molecular scattering signal $\mathrm{Nm}$ is subtracted. The signal, net of background and molecular scattering, was estimated as $\mathrm{dN}=(\mathrm{N}-\mathrm{Nf}) *(\mathrm{R}-1) / \mathrm{R}$, where $\mathrm{N}$ is the total signal, $\mathrm{Nf}$ is the total background signal, and $\mathrm{R}$ is the scattering ratio.

Figure $5 \mathrm{~b}$ shows the ionization profiles by precipitating electrons, calculated from the analytical approximation presented in $[17,18]$. A comparison of results of calculations using analytical approximations demonstrated that they agreed well with the classic results calculated by the Monte-Carlo method in [20] and the data presented in [21].

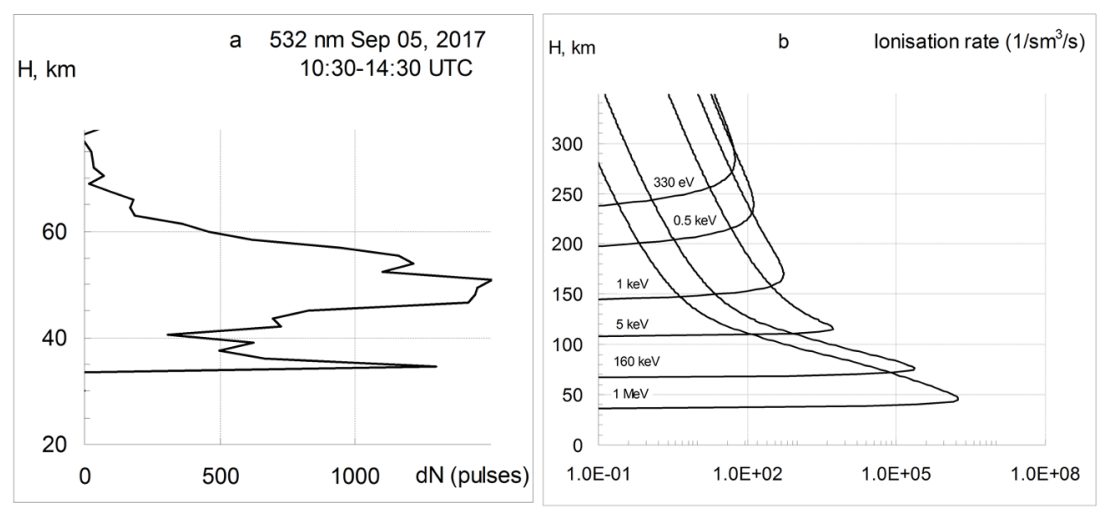

Figure 5. Exceeding above the molecular scattering signal $\mathrm{dN}$ on September 5, 2017 (a) and the ionization profiles for monoenergetic electron fluxes as a function of their energy (b).

The greatest values of the scattering ratio in Fig. $4 \mathrm{~b}$ are observed in the region of 50-65 $\mathrm{km}$ with a maximum at an altitude of $57 \mathrm{~km}$. The additional signal $\mathrm{dN}$ has a maximum in the region of $47-51 \mathrm{~km}$ and is located in the region of $40-65 \mathrm{~km}$. At these altitudes, ionization is produced by electrons with an energy of $600 \mathrm{keV}$. As shown in Section 5.1, this signal can be caused by resonant scattering by excited nitrogen atoms arising as a result of photochemical reactions associated with ionization. The discrepancy between the heights is explained by the exponential decrease in the molecular scattering coefficient with height and the increase in the relative contribution of the additional signal to the scattering ratio $\mathrm{R}$. The presence of a minimum in the profile of the additional signal at an altitude of about $40 \mathrm{~km}$ indicates the precipitation of electrons with energies close to $600 \mathrm{keV}$.

An increase in the additional signal from a height of 40 to $35 \mathrm{~km}$ allows us to conclude that there were observed precipitations of electrons with energies greater than $2.8 \mathrm{MeV}$. The monoenergetic flux of electrons with an energy of $2.8 \mathrm{MeV}$ has a maximum at an altitude of $35 \mathrm{~km}$.

The profile of the scattering ratio (Fig. 4b) is presented for altitudes greater than 25.5 $\mathrm{km}$ and $\mathrm{R}$ is close to unity in the $25-40 \mathrm{~km}$ region. The method of constructing the profile involves determining the unknown lidar constant at the minimum of the scattering ratio. It is assumed that at the height of the minimum the ratio of the scattering of aerosol is not present, and at this point the value of $\mathrm{R}$ is assumed to be equal to unity. If there is an additional signal at this point, it is also subtracted. For quantitative estimates in this region, it is necessary to have a complete signal profile in the entire stratosphere, that is, from a height of $10 \mathrm{~km}$. 
Figure $5 \mathrm{~b}$ shows the profile, normalized to unity at an altitude of $30 \mathrm{~km}$. The recorded total backscatter signal at an altitude of $30 \mathrm{~km}$ was 215462 pulses. The signal shown in Figure $5 \mathrm{a}$ is less than $1 \%$ of the total signal at altitudes of $35-40 \mathrm{~km}$. The exponential decrease in the density of the atmosphere with altitude leads to the fact that the signal from resonant scattering becomes noticeable at heights greater than $40 \mathrm{~km}$. The appearance of these layers could be caused by the precipitation of electrons with energies close to $600 \mathrm{keV}$.

Ionization in the region of the upper mesosphere $(60-80 \mathrm{~km})$ can be produced by precipitating electrons with an energy of $150-300 \mathrm{keV}$ and manifested on the scattering ratio profiles in the form of aerosol layers. The heights of the additional signal $\mathrm{dN}$ maximum and the profile maximum of the scattering ratio in this region differ insignificantly.

Aerosol layers in the upper mesosphere can be defined as imaginary.

\section{Conclusions}

It was shown the possibility to determine the energies of precipitated electrons into the atmosphere by the lidar method when sounding at the wavelength of 532 and $561.1 \mathrm{~nm}$.

The possibility of detecting resonant scattering by gas components of the middle atmosphere is shown. The possibility of forming imaginary aerosol layers in the mesosphere is substantiated.

When ionization sources appear in the atmosphere, the lidar resonance scattering signal on excited oxygen and nitrogen ions can be regarded as the sum of two processes:

- resonance scattering on excited ions formed in the result of photochemical reactions during the laser pulse presence in this region. A lidar signal from ions of this process is proportional to ionization rate;

- resonance scattering on atomic oxygen and nitrogen ions excited by precipitated electrons. A lidar signal from ions of this process is proportional to the concentration of these ions. The sum of these signals determines the form of the obtained profile and depends on the precipitated electron spectrum.

\section{Acknowledgements}

We thank OMNIWeb Data Explorer, NIST Atomic Spectra Database, United States, for granting the data on the Kp , Ap and DST planetary indexes of geomagnetic activity and atomic spectral data. The work was supported by RFBR Grant No. 16-05-00901a, RSCF Grant No. 14-11-00194.

\section{References}

[1] M. Hirono, Radio Res. Labs, 11, 250 (1965)

[2] R. A.Young, Disc. Faraday Soc, 3, 118, 209 (1964)

[3] Y. Kato, et al., Rept. Ionosphere and Space Res., Japan, 8, 103 (1964)

[4] Bowman, M.R. et al., Radio and Electr. Eng. 39, 29 (1970)

[5] R. Collins, T. Hallinan, R. Smith, G. Hernandez, GRL, 23(24), 3655-3658, (1996) DOI: 10.1029/96GL03337

[6] T. Tsuda, S. Nozawa, T. Kawahara, T. Kawabata, N. Saito, S. Wada, Y. Ogawa, S. Oyama, C. Hall, M. Tsutsumi, et al. GRL 40, 17, (2013) DOI: 10.1002/grl.50897

[7] T. Kawahara, S. Nozawa,N. Saito, T. Kawabata, T. Tsuda and S. Wada, Optics Express 25(12), A491, (2017) https://doi.org/10.1364/OE.25.00A491 
[8] R. L. Collins, D. Lummerzheim, R.W. Smith, Applied Optics 36, 24, 6024 (1997)

[9] R. L. Collins, L. Su, D. Lummerzheim, R.A. Doe, In: Characterising the Ionosphere (pp. 2-1 - 2-14), Meeting Proceedings RTO-MP-IST-056, Paper 2. Neuilly-sur-Seine, France: RTO. (2006) Available from: http://www.rto.nato.int/abstracts.asp

[10] V.V. Bychkov, Y.A. Nepomnyashchiy, A.S. Perezhogin, B.M. Shevtsov, Earth, Planets and Space, 66:150 (2014) DOI: 10.1186/s40623-014-0150-6

[11] V.V. Bychkov, Y.A. Nepomnyashchiy, A.S. Perezhogin, B.M. Shevtsov Atmospheric and Oceanic Optics 28(4), 303, (2015) DOI: 10.1134/S1024856015040041

[12] . V.V. Bychkov, A.S. Perezhogin, I.N. Seredkin, B.M. Shevtsov, SPIE Proc., 10466, 1046677, (2017), doi: 10.1117/12.2292675

[13] A. Kramida, Yu. Ralchenko, J. Reader and NIST ASD TEAM "NIST Atomic Spectra Database (ver. 5.5.2)" https://physics.nist.gov/asd, National Institute of Standards and Technology, Gaithersburg, MD (2018)

[14] V.V. Bychkov, A.S. Perezhogin, I.N. Seredkin, B.M. Shevtsov, Proc. 10035, 100355R, (2016) DOI: $10.1117 / 12.2248674$

[15] P.J. Richards, JGR, 116, A08307, (2011) doi:10.1029/2011JA016613

[16] V.V. Bychkov, A.S. Perezhogin, A.S. Perezhogin, B.M. Shevtsov, V.N. Marichev, G.G. Matvienko, A.S. Belov and A.A. Cheremisin, Atmospheric and Oceanic Optics, 25, 3, (2012) doi: 10.1134/S1024856012030037

[17] M.G. Deminov “Earth's ionosphere” in: Plasma heliogeophysics, M:Fizmatlit, Moscow, 2, 92 (2008)

[18] M.G. Deminov, V.V. Chegai, Geomagnetism and aeronomy, 20, 1, (1980)

[19] N.N. Shefov, A.I. Semenov, V.Yu. Chomich, Radiation of the upper atmosphere - an indicator of its structure and dynamics, (GEOS, Moscow, 2006)

[20] Rees, M. N., Benedict, P. C.: 1970, J. Geophys. Res. 75, 1763

[21] Omholt, A., Stoffregen, W., Derblum, H.: 1962, J. Atmosph. Terr. Phys, 24, 203 